\title{
Errors, omissions and medication patterns of handwritten outpatient prescriptions in Bangladesh: a cross-sectional health survey
}

\author{
Md. Uzzal Haque ${ }^{1}$, S.M. Abdul Barik², Shamiul Bashar², Rashedul Islam², Samia Bashar², Anup Kumar², Abid Hasan \\ Dipon $^{2}$, Nurunnahar Kona ${ }^{2}$, Aktar Uzzaman Chouduri ${ }^{3 *}$ \\ ${ }^{1}$ Department of Pharmacy, Jessore University of Science and Technology, Jessore, Bangladesh. ${ }^{2}$ Department of Pharmacy, Varendra University, Rajshahi, \\ Bangladesh. ${ }^{3}$ Department of Pharmacy, Faculty of Science, University of Rajshahi, Rajshahi, Bangladesh.
}

\begin{tabular}{|c|c|}
\hline ARTICLE INFO & ABSTRACT \\
\hline Article history: & \multirow{11}{*}{$\begin{array}{l}\text { Handwritten prescription errors are worldwide common problem. We investigated the types and extent of } \\
\text { prescription errors in three cities of Bangladesh. Total } 900 \text { outpatient prescriptions were surveyed following the } \\
\text { guidelines of WHO and BNF. Prescription errors in superscription, inscription and subscription were analyzed } \\
\text { by Microsoft Excel } 2010 \text {. About } 73 \% \text { patients visited MBBS and } 8 \% \text { BDS doctors. The male outpatients (55\%) } \\
\text { were slightly higher than female (45\%). Commonly found errors of prescription were in superscription part, i.e. } \\
\text { gender }(64.33 \%) \text {, age }(17.67 \%) \text { and name }(5 \%) \text { of the patients. In inscription part, most common error was the } \\
\text { direction for drug use }(42 \%) \text { followed by the dosage regimens }(28 \%) \text {, doses }(26 \%) \text {, and dosage forms ( } 12.67 \%) \\
\text { of the drug. In subscription part, illegible handwriting was most common }(46 \%) \text { followed by the prescribers sign } \\
(10.67 \%) \text { and date ( } 4 \%) \text {. In a single prescription, averagely } 3 \text { and maximally } 8 \text { drugs were found to be } \\
\text { prescribed. Most frequently prescribed drugs were antibiotics (18.25\%) followed by antacids (17.45\%) and } \\
\text { NSAIDs (13.60\%). Errors in handwritten prescriptions are the primary causes of treatment failure in } \\
\text { Bangladesh. More professional care by the prescribers' and the inclusion of pharmacists in hospital can only } \\
\text { reduce the errors and assure safer health. }\end{array}$} \\
\hline Received on: $26 / 03 / 2016$ & \\
\hline Revised on: 19/04/2016 & \\
\hline Accepted on: 04/05/2016 & \\
\hline Available online: $28 / 06 / 2016$ & \\
\hline Key words: & \\
\hline Outpatients, doctors, & \\
\hline handwritten prescriptions, & \\
\hline prescription errors, & \\
\hline Bangladesh. & \\
\hline & \\
\hline
\end{tabular}

\section{INTRODUCTION}

Writing prescription is an important skill of a doctor which needs sound medical knowledge about diseases and drugs. The health care system in Bangladesh has not reached at a desired level although the quality of medicine is good enough. One of the reasons of the undesired health care system in Bangladesh is prescription errors. Prescription, an order written by doctors for patients, contains directions for pharmacists to compound or/and dispense medications regarding patients' consumption (Tripathi, 2008). A prescription has four parts- (a) superscription which includes date, name, address, age of patients, symbol Rx for recipe, (b) inscription which is the body of a prescription that specifies the name and amount of each ingredient, dosage forms, strengths and route of administration,

* Corresponding Author

Email:auchow5@yahoo.com (c) subscription which gives the directions to the pharmacists for compounding and dispensing, (d) transcription/signature which gives instructions to the patient on how, how much, when, how long the drug is to be taken (Haavik et al., 2011). Prescription errors are generally classified into three major types, viz. superscription errors, inscription errors, and subscription errors that have various detrimental effects to patients and therapy (Jeetu and Girish, 2010). Therefore, a prescription should be written carefully and clearly to avoid such detrimental consequences and consummate regarding all legal requirements (Lesar et al., 1997; Dean et al., 2005). Errors may occur anywhere between prescribing to administration of drug. Therefore, medication safety is considered as the top priority for the patient's healthcare. Of all the medication errors, prescription errors are more common although preventable (Ansari and Neupane, 2009). The process of prescription generation and dispensing is governed by regulatory systems, the purpose of which is to maximize the safety and efficacy of the product supplied. 
Community pharmacists have an important role in checking prescriptions to ensure that they are appropriate to dispense (Shah et al., 2001). Prescription errors have been identified and documented worldwide by many researchers but very little coverage on Bangladesh is available.

One study shows that $15-21 \%$ prescriptions bear at least one prescribing error (Jeetu and Girish, 2010). About 7.1\% prescribing errors were detected in another survey carried out at a teaching hospital in Saudi Arabia out of 1580 prescriptions (Al-Dhawailie, 2011). A similar and separate study carried out at a hospital in India reported that out of 304 prescriptions $34 \%$ had at least one error and 5\% were incorrect (Pote et al., 2007).

At a primary healthcare center in Riyadh city $18.7 \%$ prescriptions were found to be erroneous (Khoja et al., 2011) and at a government hospital in Indonesia out of 229 outpatient prescriptions $98.69 \%$ were with medication errors (Perwitasari et al., 2010). A survey report on prescription errors drew the conclusion that the increased rate of prescription errors was evolved from the handwritten prescriptions and pharmacists need to clarify $1-5 \%$ of prescriptions (Dean et al., 2005). A review article states that patient's outcomes can be improved by the intervention of pharmacists (Lewis et al., 2009). Friedman et al showed that not only the pharmacist's role in dispensing process but also the policies and procedures should be implemented to prevent errors (Friedman et al., 2007). Moreover, the pharmacist's intervention can considerably reduce the cost of therapy, the adverse reactions of drugs and improve total health system of a certain region. In several reports it has been emphasized that the interdisciplinary communication and cooperation is necessary in identifying and resolving prescription errors to achieve optimal therapeutic outcomes for the patients (Alam et al., 2006; Aronson, 2009a; Aronson, 2009b). The literature review has shown that there are no enough reports about the epidemiology of prescription errors of omission for outpatients in Bangladesh. Therefore, the present study was undertaken to investigate the prevalence, frequency and nature of outpatient prescription errors in three cities of Bangladesh and to provide valuable suggestions to avoid these errors for the benefit and safety of patients.

\section{METHODS}

\section{Study site and period of survey}

Three cities viz. Rajshahi, Naogaon and Bogra of Bangladesh pointed in the country map (Figure 1) were selected for collecting data over six month period of January to December, 2014 (http://en.wikipedia.org/wiki/Rajshahi, http://en.wikipedia.org/wiki/Naogaon, http://en.wikipedia.org/wiki/Bogra).

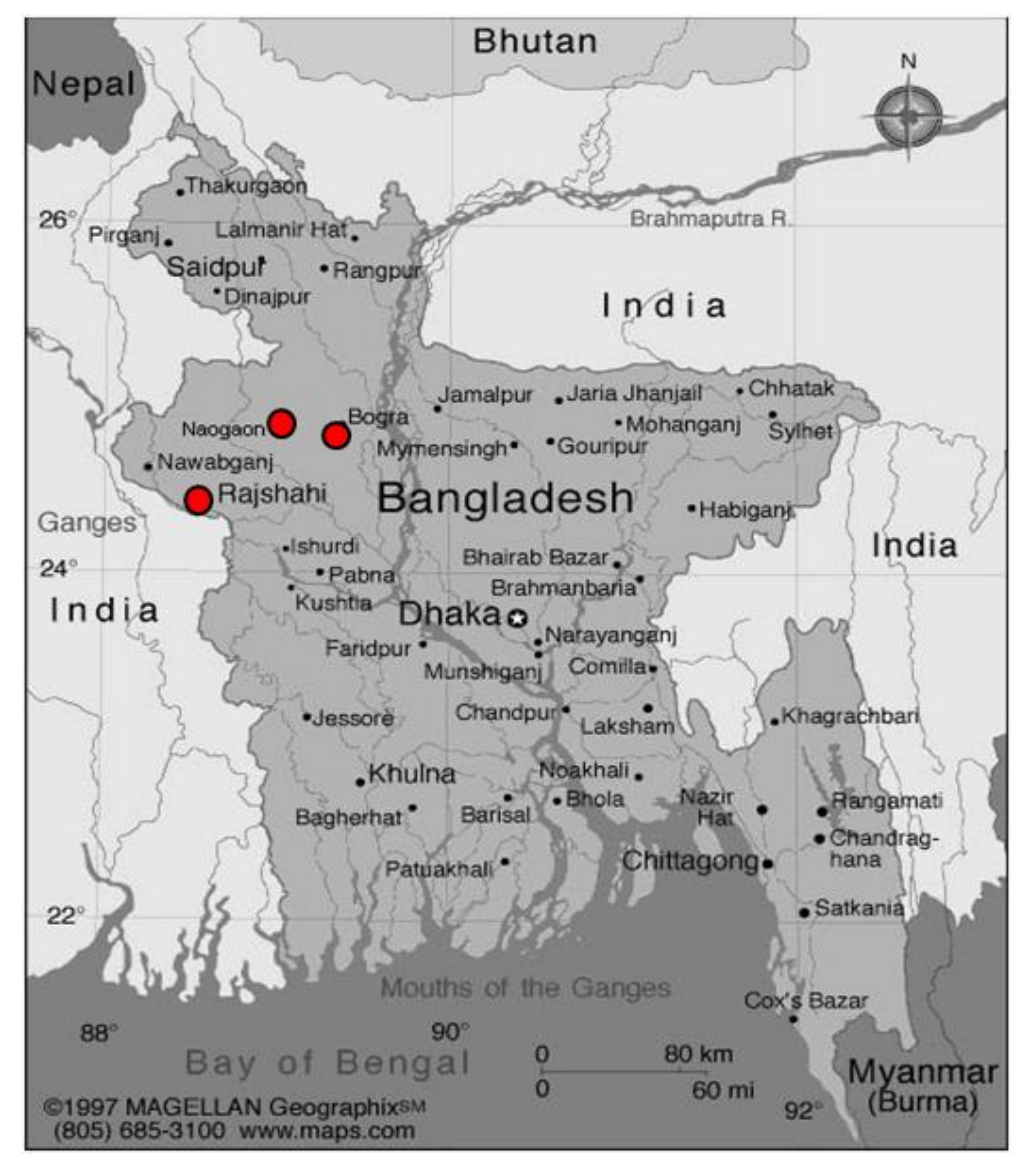

Fig. 1: Survey sites on country map

Three cities, Rajshahi, Naogaon and Bogra, are marked with red color filled circles. 


\section{Data collection}

This survey was carried out with a self-designed standard questionnaire by directly interviewing patients of Rajshahi, Naogaon and Bogra cities, 300 outpatients were taken from each city. Volunteer students of the Department of Pharmacy, Varendra University were assigned and given instruction to do the survey. The written consent was taken from each patient during study. Data were collected at the pharmacies by randomized manner when patients were purchasing drugs and the prescribing doctors were not informed about the study due to avoid the interference of the data collection process. The prescriptions were analyzed following WHO standard treatment guidelines and British National Formulary using Microsoft Office Excel 2010 software. The omission errors include superscription, inscription and subscription errors and identified according to the method described by Al-Shahaibi et al (Al-Shahaibi et al., 2012). The superscription errors of omission are classified based on the information omitted on patients' age, name and gender. The inscription errors include absence of dose, dosage form and dosage regimen of the drugs and incomplete directions for drug use. The subscription errors include illegible hand writing, prescriber's signature, and date of prescription (Al-Shahaibi et al., 2012). The percentage of all the errors were calculated for individual cities and finally expressed as mean $\pm \mathrm{SD}$. The frequencies of different class of drugs prescribed in prescriptions were analyzed such as antibiotics, antacids, multivitamins and minerals, non-steroidal anti-inflammatory drugs (NSAIDs), antihistamines, antipyretics, cardiovascular drugs, oral contraceptives, antiemetic drugs, skin drugs, cough expectorants, bronchodilators, anti-diabetics, etc. (Calligaris et al., 2009).

\section{Ethical considerations}

The survey was conducted following the section 12 of WMA declaration of Helsinki and this study was also logistically supported by the Department of Pharmacy, Varendra University and Rajshahi University, Bangladesh. As the human subjects did not use any hazardous agents during the study and only participated in the interview of the patient so this survey based research did not require any further permission from institutional ethics committee.

\section{Statistical analysis}

Descriptive statistics were applied to the collected data using Microsoft Excel Software 2010. Results were expressed graphically in percentages, means and standard deviations (SD).

\section{RESULTS}

\section{Epidemiology}

This survey based study conducted in three cities of Bangladesh viz. Rajshahi, Naogaon, and Bogra, revealed that about $55 \%$ of outpatients were males and $45 \%$ were females. Almost the same statistics of patients' gender were seen in all test cities (Table 1). Among the patients $(n=900)$ under survey, averagely $73 \%$ visited MBBS doctors and $8 \%$ visited BDS doctors. It is noticeable that a large number of patients $(19 \%)$ visited quack doctors although the survey sites were metropolitan city and district city areas. However, no doubt, this number will be larger in village or city side area. Among three test cities, the average number of patients visiting MBBS doctors in Rajshahi was higher $(79 \%)$ than that of Naogaon $(69 \%)$ and Bogra $(71 \%)$ since Rajshahi is a metropolitan city with more available hospital and clinic facilities than two other cities.

Table 1: Gender variability and health care professionals of collected outpatient prescriptions

\begin{tabular}{llcccc}
\hline \multirow{2}{*}{ Variables } & & Rajshahi & Naogaon & Bogra & Mean \pm SD \\
\cline { 3 - 6 } & & \multicolumn{2}{c}{ Frequency of variables $(\%)$} \\
\hline Gender & Male & 56 & 55 & 54 & $55 \pm 0.67$ \\
& Female & 44 & 45 & 46 & $45 \pm 0.67$ \\
Doctors & MBBS & 79 & 69 & 71 & $73 \pm 4.00$ \\
& BDS & 8 & 6 & 10 & $8 \pm 1.33$ \\
\hline
\end{tabular}

MBBS: Bachelor of Medicine and Bachelor of Surgery, BDS: Bachelor of Dental Surgery

\section{Errors and omissions in prescription}

The prescriptions were analyzed for superscription, inscription and subscription errors by following WHO standard treatment guidelines and British National Formulary with the help of Microsoft Office Excel 2010 software and the error of omissions was expressed as means. The highest error of omissions was found in the part of superscription in which the absence of patients' gender (64.33\%) was most frequently occurred (Table 2). The second highest superscription error was the omission of patients' age (17.67\%) and the third highest error under this category was the absence of patients' name (5\%). In inscription errors, the dose of drug was found to be omitted in about $26 \%$ of prescriptions, the dosage form of medication was omitted in $12.67 \%$ of prescriptions, the dosage regimen of drug was omitted in $28 \%$ of prescriptions and the complete direction for drug use was omitted in $42 \%$ of prescriptions. In subscription errors, the prescribers' signature was omitted in $10.67 \%$ of prescription, while the date of prescription was omitted in $4 \%$ of prescription and illegible handwriting was found in $46 \%$ of prescription. Among three cities the prescription error of omissions was less frequent in Rajshahi than Naogaon and Bogra.

\section{General medication pattern}

A total of 2619 drugs were prescribed in 900 outpatient prescriptions where averagely 3 drugs were given to a patient. A variety of drugs were prescribed and in a single prescription maximally eight drugs were found to be prescribed. However, only the drugs with frequencies higher than $1 \%$ of total prescribed drugs were depicted in figure 2 . The type of drugs with highest frequency of occurrence in prescriptions was antibiotics $(18.25 \%)$, the second highest type of drugs was antacids $(17.45 \%)$ and the third highest type was NSAIDS (13.60\%). This result indicated that infections and/or gastroenteritis accompanying with pain/inflammation were the most common health complications of patients in these cities. Multivitamins and minerals, cardiovascular 
drugs, antipyretic drugs, antihistamines and antidiabetic drugs were also common in prescriptions that were $12.50 \%, 10.85 \%$, $6.4 \%, 5.04 \%$ and $3.92 \%$, respectively (Figure 2). The therapeutic application of multivitamins and minerals is generally wide in the treatment of diseases which was found to be $12.50 \%$ but cardiovascular drugs which were quite disease-specific were found to be $10.85 \%$. Thus, the obtained result implicated that the prevalence of cardiac patients were significantly higher in study areas. Furthermore, bronchodilators, antiemetics, skin drugs, cough expectorants, oral contraceptives and corticosteroids were drugs with low frequencies that were $2.7 \%, 1.9 \%, 0.99 \%, 0.9 \%$, $0.9 \%$ and $0.6 \%$, respectively.

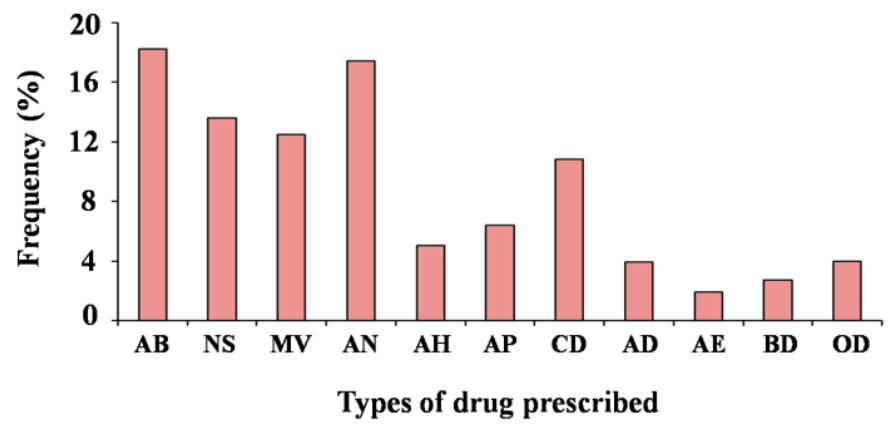

Fig. 2: Various categories of medication in prescriptions

AB: Antibiotics, NS: NSAIDs, MV: Multivitamins, AN: Antacids, AH: Antihistamines, AP: Antipyretics, CD: Cardiovascular drugs, AD: Antidiabetics, AE: Antiemetics, BD: Bronchodilators, OD: Other drugs.

\section{DISCUSSION}

In this study the average number of male outpatients was found to be higher than that of female outpatients which cannot be fully explained although we think medical decisions are being biased by the male because of their dominance character in Bangladesh. A large number of patients $(73 \%)$ visited MBBS doctors in the study areas since two large public medical college and hospitals were present there in Rajshahi and Bogra districts, and also a public general hospital in Naogaon, where patients could easily see the MBBS doctors.

The research report suggests that the frequency of error increases with an increasing number of drugs (Calligaris et al., 2009). The reasons of this diversity may be due to the huge number of patients against the available number of doctors, patients having multiple complications, doctors' trend to achieve a target forced by the pharmaceutical marketing policy, and the different geographical region of the study

The highest superscription error of omission was the gender of patients $(64.33 \%)$ which has a great impact on the medication. For example, some medications react faster/better in female patients than males. So, missing gender in a prescription can interrupt the proper treatment of patient. The second highest superscription error of omission was patient's age (17.67\%) which is very important in terms of dose and dosage form. This error of omission falls in line with the study carried out in Nepal (Alam et al., 2006) and lowers than other study (52.4\%) carried out in
Indonesia (Perwitasari et al., 2010). In inscription, the highest number of omissions was observed on the direction for drug use $(42 \%)$ which was written obscurely that may lead to dispensing errors. The dosage regimen of the drug, which would help to reach the therapeutic target and prevent adverse effects, were missed in $28 \%$ of prescriptions that were almost equal to other studies in India and Indonesia (Perwitasari et al., 2010; Inamdar et al., 2014). However, the missing of dose and dosage form in prescriptions were $26 \%$ and $12.67 \%$, respectively which were relatively high to other study conducted in Bangladesh (Biswas et al., 2014).

As shown in table 2, the highest frequency of subscription error of omissions was obscure handwriting of the physician which was $46 \%$. In practice it may create serious problems to the retail pharmacist who sometimes misinterprets or even dispenses wrong medicine to the patients. The prescriber's signature is imperative, without it the drug cannot be dispensed to the patient. Here the frequency of occurrence of this error was 2 fold higher (10.67\%) than that of other similar studies (5\%) (Shah et al., 2001; Marwaha et al., 2010). However, another type of error occurring considerably in lower extent is the date of prescription (4\%). The date of prescription is essential part of record. In case a patient suffers from an adverse reaction or the therapy is not being effective, the date could indicate when the patient started the therapy. The frequency of occurrence of this error (4\%) was higher than a study carried out in India $(1.02 \%)$ and lower than a study carried out in Indonesia (7.42\%) (Shah et al., 2001; Perwitasari et al., 2010).

Table 2: Omission errors in outpatient prescriptions.

\begin{tabular}{|c|c|c|c|c|}
\hline Variables & 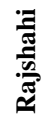 & 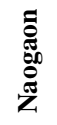 & ف) & Mean \pm SD \\
\hline Superscription errors & \multicolumn{4}{|c|}{ Frequency of variables (\%) } \\
\hline Patients' name missing & 4 & 6 & 5 & $5.00 \pm 0.67$ \\
\hline Patients' age missing & 15 & 20 & 18 & $17.67 \pm 1.78$ \\
\hline Patients' gender missing & 61 & 65 & 67 & $64.33 \pm 2.22$ \\
\hline \multicolumn{5}{|l|}{ Inscription errors } \\
\hline Dose missing & 20 & 31 & 27 & $26.00 \pm 4.00$ \\
\hline Dosage form missing & 10 & 16 & 12 & $12.67 \pm 2.22$ \\
\hline Incomplete dosage regimen & 26 & 30 & 28 & $28.00 \pm 1.33$ \\
\hline Incomplete direction for drug use & 37 & 50 & 39 & $42.00 \pm 5.33$ \\
\hline \multicolumn{5}{|l|}{ Subscription errors } \\
\hline Prescriber signature missing & 8 & 11 & 13 & $10.67 \pm 1.78$ \\
\hline Date of prescription missing & 3 & 5 & 4 & $4.00 \pm 0.67$ \\
\hline Illegible hand writing & 42 & 46 & 50 & $46.00 \pm 2.67$ \\
\hline
\end{tabular}

The implications of our findings are significant. First, it is clear that handwritten outpatient prescription errors of omission are abundant in Bangladesh as found in different countries of the world (Shah et al., 2001; Perwitasari et al., 2010; Bates et al., 2001; Meyer, 2000). Second, the handwritten prescription errors could be avoided by using computerized prescriptions and supportive software. Third, retail pharmacist has a significant role 
to play in avoiding prescription errors and to improve the patient care services by working together with all health professionals.

\section{CONCLUSIONS}

The antibiotics were the most frequently prescribed drugs followed by antacids and NSAIDs. Serious prescription errors were dose, dosage form, dosage regimen of drugs which can be the causes of treatment failure in Bangladesh specifically for the infections. The prescribers need to be more professional in writing prescriptions and pharmacists intervention in hospital can only reduce the errors.

\section{LIMITATIONS OF STUDY}

The study was carried out in three cities of the northern part of Bangladesh which cannot reflect the generalized prescribing practices of the whole country.

\section{LIST OF ABBREVIATIONS}

MBBS: Bachelor of medicine and bachelor of surgery; BDS: Bachelor of dental surgery; NSAIDs: Non-steroidal antiinflammatory drugs; WMA: World medical association; BNF: British National Formulary.

\section{CONFLICT OF INTERESTS}

The authors declare that they have no competing interests.

\section{AUTHORS’ CONTRIBUTIONS}

All authors have substantially contributed to the research. Specifically MUH and NK coordinated in the survey part; SMAB, $\mathrm{SB}, \mathrm{RI}, \mathrm{SB}, \mathrm{AK}$ and AHD contributed in data collection; AUC analyzed the data and drafted the manuscript.

\section{ACKNOWLEDGEMENTS}

Authors wish to thank the students of Department of Pharmacy, Varendra University and Rajshahi University, Bangladesh for their support in data collection from outpatient prescriptions.

\section{REFERENCES}

Alam K, Mishra P, Prabhu M, Shankar PR, Palaian S, Bhandari $\mathrm{RB}$, Bista D. A study on rational drug prescribing and dispensing in outpatients in a tertiary care teaching hospital of Western Nepal. Kathmandu Univ Med J, 2006; 4:436-443.

Al-Dhawailie AA. Inpatient prescribing errors and pharmacist intervention at a teaching hospital in Saudi Arabia. Saudi Pharm J, 2011; 19:193-196.

Al-Shahaibi NM, Al-Said LS, Kini TG, Chitme HR. Identifying errors in hand written outpatient prescriptions in Oman. J Young Pharm, $2012 ; 4: 267-272$

Ansari M, Neupane D. Study on determination of errors in prescription writing. Kathmandu Univ Med J, 2009; 7:238-241.

Aronson JK. Medication errors: definitions and classification. Br J Clin Pharmacol, 2009a; 67:599-604.

Aronson JK. Medication errors: what they are, how they happen, and how to avoid them. Q J Med, 2009b; 102:513-521.
Bates DW, Cohen M, Leape LL, Overhage JM, Shabot MM, Sheridan T. Reducing the frequency of errors in medicine using information technology. J Am Med Inform Assoc, 2001; 8:299-308.

Biswas M, Roy DN, Islam M, Parvez GMM, Rahman MM, Tajmim A, Ferdiousi N, Ali M, Nasim SM. Prevalence and nature of handwritten outpatients prescription errors in Bangladesh. Int J Prarm Pharm Sci, 2014; 6:126-130.

Bogra city. Available at: http://en.wikipedia.org/wiki/Bogra [accessed 20 January 2016].

Inamdar SZ, Rucha K, Kotnal RB, Kulkarni RV, Simpi CC Singh A, Reddy AG, Jagdeesh P, Manitheja K, Arun N, Vishal B. Assessment of nonconformity to prescription writing requirements and prescription errors: a community based study. Ind J Pharm Prac, 2014 7:36-41.

Calligaris L, Panzera A, Arnoldo L, Londero C, Quattrin R, Troncon MG, Brusaferro S. Errors and omissions in hospital prescriptions: a survey of prescription writing in a hospital. BMC Clin Pharmacol, 2009; $9: 9$

Dean FB, Vincent C, Schachter M, Barber N. The incidence of prescribing errors in hospital inpatients: an overview of the research methods. Drug Saf, 2005; 28:891-900.

Friedman AL, Geoghegan SR, Sowers NM, Kulkarni S, Formica RN. Medication errors in the outpatient setting, classification and root cause analysis. Arch Surg, 2007; 142:278-283.

Haavik S, Soeviknes S, Erdal H, Kjonniksen I, Guttormsen AB, Granas AG. Prescriptions from general practitioners and in hospital physicians requiring pharmacist's interventions. Pharmacoepidemiol Drug Saf, 2011; 20:50-56.

Jeetu G, Girish T. Prescription drug labeling medication errors. A big deal for pharmacists. J Young Pharm, 2010; 2:107-111.

Khoja T, Neyaz T, Qureshi NA, Magzoub MA, Haycox A, Walley T. Medication errors in primary care in Riyadh city, Saudi Arabia East Mediterr Health J, 2011; 17:156-159.

Lesar TS, Briceland L, Stein DS. Factors related to errors in medication prescribing. JAMA, 1997; 277:312-317.

Lewis PJ, Dornan T, Taylor D, Tully MP, Wass V, Ashcroft DM. Prevalence, incidence and nature of prescribing errors in hospital inpatients: A systematic review. Drug Saf, 2009; 32:379-389.

Marwaha M, Marwaha RK, Wadhwa J, Padi SSV. A retrospective analysis on a survey of handwritten prescription errors in general practice. Int J Pharm Pharm Sci, 2010; 2:80-82.

Meyer TA. Improving the quality of the order-writing process for inpatient orders and outpatient prescriptions. Am J Health-Syst Pharm, 2000; 57:S18-S22.

Naogaon city. Available at: http://en.wikipedia.org/wiki/Naogaon [accessed 20 January 2016].

Perwitasari DA, Abror J, Wahyuningsih I. Medication errors in outpatients of a government hospital in Yogyakarta Indonesia. Int J Pharm Sci Rev Res, 2010; 1:8-10.

Pote S, Tiwari P, Dcruz S. Medication prescribing errors in a public teaching hospital in India: A prospective study. Pharm Pract (Granada), 2007; 5:17-20.

Rajshahi city. Available at: http://en.wikipedia.org/wiki/Rajshahi [accessed 20 January 2016].

Shah SNH, Aslam M, Avery AJ. A survey of prescription errors in general practice. Pharm J, 2001; 267:860-862.

Tripathi KD. 2008. Essentials of medical pharmacology, 6th Edition, Jaypee Brothers Medical Publishers, New Delhi, India pp. 03

\section{How to cite this article:}

Haque MU, Barik SMA, Bashar S, Islam R, Bashar S, Kumar A, Dipon AH, Kona N, Chouduri AU. Errors, omissions and medication patterns of handwritten outpatient prescriptions in Bangladesh: a cross-sectional health survey. J App Pharm Sci, 2016; 6 (06): 042-046. 